\title{
Development of technology for obtaining a liquid extract of medicinal sage (Salvia officinalis L.)
}

\author{
Anastasia Moldavanova*, Anastasia Malyutina, Larissa Kozubova, Valentina Kazakova, and \\ Natalia Shestopalova \\ ${ }^{1}$ Belgorod State National Research University, 308015, Belgorod, Russia
}

\begin{abstract}
Inflammatory diseases of the female genital area are dominant among the total number of gynecological diseases. Among all the variety of medicinal plant materials used in official medicine, salvia medicinal draws attention to itself, which has repeatedly proved its effectiveness in the treatment of inflammatory diseases of the mucous membranes of various origins. That is why the goal was set to develop a technology for obtaining a liquid extract from the leaves of Salvia officinalis L. As a result of the study, a method was developed for obtaining a liquid extract by selecting the optimal extraction conditions. It was found that the optimal raw materialextractant ratio is 1:50, the optimal concentration of the extractant ethyl alcohol is $70 \%$, the infusion time of the extract is 24 hours. To intensify the extraction process, the method of ultrasonic processing of raw materials at the soaking stage was used. The optimal time for processing plant materials with ultrasound was 45 minutes. As a result of using this method to obtain a liquid extract from the leaves of sage officinalis, the yield of phenolic compounds was doubled in comparison with obtaining an extract without sonication of raw materials and amounted to $182.7 \mathrm{mg} / \mathrm{g}$ of flavonoids in terms of luteolin-7-glycoside.
\end{abstract}

Keywords: Salvia officinalis L, technology, liquid extract, medical sage.

\section{Introduction}

According to the analysis of the pharmaceutical market in the Russian Federation, about 25\% of all drugs are herbal drugs [1]. According to forecasts of leading world scientists, interest in herbal medicines will increase, as there is a tendency to increase preventive measures to prevent diseases for which herbal medicines are ideally suited, due to their mild action, efficacy, safety and natural origin [2]. In particular, drugs in this group are suitable for the treatment and prevention of diseases of the female genital area. According to previously obtained data [3], it was found that for the treatment of inflammatory diseases of the pelvic organs, drugs from the group of antibiotics (33\%) and antiseptics (17\%) are more often prescribed. Analysis by groups of dosage forms showed that soft dosage forms rank first and account for $47 \%$ of the total number of drugs. The leaders in this group are suppositories with a market share of $87 \%$, including vaginal ones - $62 \%$. Among solid dosage forms, which account for $33 \%$ of the total number of drugs, the largest share is occupied by tablets for

\footnotetext{
* Corresponding author: moldavanova@bsu.edu.ru
} 
internal use and vaginal tablets, which together account for $48 \%$. Liquid dosage forms account for $16 \%$, within the group the leaders are solutions for internal, external and local use $-74 \%$. Medicinal herbal raw materials for the treatment of vulvitis and vulvovaginitis are represented by fees and account for only $4 \%$ of the total market share of medicines. As the assortment analysis of the domestic drug market has shown, there is currently a shortage of herbal remedies for the treatment of vulvitis.

Phytopreparations have a complex effect on this disease. They can be used as an independent agent for the prevention of chronic gynecological diseases of an inflammatory nature, and as part of an auxiliary therapy to essential drugs. Medicinal sage (Salvia officinalis L.) is a pharmacopoeial plant of the genus Lamiaceae. In the Russian Federation, the pharmacopoeial raw material is the leaves of the medicinal sage (Salviae officinalis folia). The pharmacological activity of the leaves of Salvia officinalis is quite wide. It has antioxidant, antibacterial, antiviral, antifungal, anti-inflammatory, hypotensive, antispasmodic, diuretic and astringent effects $[3,4,5]$. The biological activity of sage is due to a complex of biologically active substances (BAS). These include volatile compounds, phenolic compounds, and vitamins. Volatile compounds include components of sage essential oil - monoterpenes - $\alpha$ - and $\beta$-thujone, camphor, 1,8-cineole, borneol and sesquiterpenes - humulene and $\beta$-caryophyllene [6,7]. Phenolic compounds are represented by phenol carboxylic acids and their derivatives, flavonoids and tannins [8,9,10]. Among phenolcarboxylic acids, these are chlorogenic, rosmarinic, caffeic and ferulic acids. Qualitative composition of flavonoids - quercetin, luteolin, apigenin and their glycosides. Also, hydrolyzable tannins predominate in the plant composition $[10,11]$.

Due to such a multicomponent composition of Salvia officinalis L., its high biological activity and wide application are determined. Salvia officinalis is best known for its essential oil, however, the literature indicates a fairly high content of the sum of phenolic compounds contained in the plant, represented by hydroxycinnamic acids, flavonoids, tannins. In turn, this class of compounds has a number of pharmacological effects (moderate antibacterial, anti-inflammatory, antioxidant effects, etc.), which realize their effect regardless of the content of essential oil in Salvia officinalis L. and suggests the development of a liquid extract, the dominant component of which is precisely phenolic compounds. Also, an undeniable advantage is simpler methods for extracting the sum of phenolic compounds from medicinal plant materials, available, well-studied extractants, methods for analyzing the obtained extract do not require specific expensive equipment and reagents, they are simple enough to be performed in any laboratory. It follows from this that the development of new drugs based on an extract from the leaves of sage medicinal is promising for use in the treatment and prevention of gynecological diseases.

A review of scientific literary sources showed that at the moment there are no drugs on the Russian pharmaceutical market based on sage leaf extract for gynecological use. That is why the purpose of this work was to develop a technology for obtaining a liquid extract from the leaves of Salvia officinalis L.. The patent search showed that today only one method of obtaining the extract is mentioned according to the patent of Ukraine, described in the source [12]. According to the method, the extract is obtained using an organic extractant ethyl acetate, as well as purification of the resulting extract using hexane or gasoline, which has a number of its disadvantages, such as the content of residual organic substances in the extract, which can lead to various pathological reactions, since they are aggressive for a living organism, being non-electrolytes [13]. As a result of intoxication, the blood system, the nervous and endocrine system, suffers first of all. Adverse reactions of intoxication in children and adolescents are especially pronounced. As a result of chronic intoxication, nonspecific immune defense decreases, which in turn leads to many diseases of both allergic and non-allergic nature [14]. In the method developed by us, these disadvantages are absent. 


\section{Materials and methods}

The object of the study was crushed sage leaves with a particle size of $0.1-2 \mathrm{~mm}$, harvested by Krasnogorskleksredstva LLC, Krasnogorsk, Russia. Series 80420, valid until 05/2022, the raw material met the requirements of FS.2.5.0051.15 Salvia officinalis leaves.

\subsection{Extraction methods}

Extraction was carried out by the method of simple maceration and maceration with sonication of the raw material at the stage of soaking. The extractant was ethyl alcohol. Maceration was carried out with the selection of optimal conditions for extraction according to the following parameters: concentration of the extractant ethyl alcohol $(40 \%, 70 \%, 96 \%)$, hydromodule (1:10, 1:30, 1:50), extraction time (18 hours, 24 hours, 72 hours). To intensify the extraction process, we used additional sonication on a Bandelin SONOPULS HD 3200 installation, ultrasound frequency $20 \mathrm{kHz}$, emitter power $280 \mathrm{~W}$, temperature $25^{\circ} \mathrm{C}$. The sonication time was selected ( $25 \mathrm{~min}, 35 \mathrm{~min}, 45 \mathrm{~min}, 55 \mathrm{~min}$ ).

A weighed portion of the raw material, crushed to a particle size of $0.1-1 \mathrm{~mm}$, was poured with an extractant and insisted for a predetermined amount of time. When using ultrasound, the soaked raw materials were processed for a predetermined amount of time. The resulting extracts were analyzed quantitatively by differential spectrophotometry by the complexation reaction with a solution of $5 \%$ aluminum chloride in a solution of $96 \%$ ethyl alcohol. $1 \mathrm{ml}$ of the obtained alcohol-water extract was placed in a $25 \mathrm{ml}$ flask, $5 \mathrm{ml}$ of a $5 \%$ alcohol solution of aluminum chloride, $1 \mathrm{ml}$ of an aqueous solution of acetic acid $9 \%$ were added, the volume of the solution was brought to the mark with $96 \%$ ethyl alcohol. The optical density of the resulting solution was measured after $45 \mathrm{~min}$ on an SF-104 spectrophotometer at a wavelength of $400 \mathrm{~nm}$ in a cuvette with a layer thickness of $10 \mathrm{~mm}$. As a reference solution, a solution was prepared consisting of $5 \mathrm{ml}$ of a $5 \%$ alcohol solution of aluminum chloride, $1 \mathrm{ml}$ of an acetic acid solution, and the volume of the solution was brought to the mark with $96 \%$ ethyl alcohol. The content of the sum of flavonoids in the obtained extract, in terms of luteolin-7-glycoside (cinnaroside) (as the main flavonoid contained in plant raw materials [15]), was calculated by the formula (1) [16]:

$$
X=\frac{D_{x} \times V_{1} \times V_{2} \times 100}{E_{1 \mathrm{c}}^{1 \%} \times m \times V_{3} \times(100-W)}
$$

(1)

где, $D_{x}$ - optical density of the resulting solution, $\mathrm{nm} ; V_{1}$ - volume of solution A, ml; $V_{2}$ - volume of solution $\mathrm{B}, \mathrm{ml} ; E_{1 \mathrm{~cm}}^{1 \%}$ - specific absorption index of the complex of aluminum chloride with luteolin-7-glycoside at a wavelength of $400 \mathrm{~nm}\left(E_{1 \mathrm{~cm}}^{1 \%}=145\right) ; m$ - weight of raw materials, $\mathrm{g} ; V_{3}$ - volume of an aliquot taken from solution $\mathrm{A}, \mathrm{ml} ; W$ - loss in mass during drying of raw materials, $\%$.

\section{Results and discussions}

In the first phase of the experiment, a comparison was made of the yield of flavonoids from the leaves of Salvia officinalis, depending on the hydromodule. Were selected ratios of raw materials - extractant 1:10, 1:30 and 1:50. Analysis based on the hydromodule showed that the largest amount of flavonoids comes out of the raw material at a raw material-extractant ratio of 1:50. Under this condition, the yield of flavonoids is almost doubled in comparison with the hydromodule 1:10. Therefore, further hydromodule 1:50 was chosen as one of the main parameters. The next stage of work was the selection of the optimal concentration of the extractant - ethyl alcohol. Extraction was performed with $40 \%, 70 \%$ and $96 \%$ ethanol. The 
best yield of substances was observed when $70 \%$ ethanol was used, which is very typical for compounds of this group.

Further, a study of the time of infusion of raw materials was carried out. The infusion was carried out for 12 hours, 24 and 72 hours. An increase in the infusion time from 24 to 72 hours did not lead to a statistically significant change in the percentage of substances in the extraction, therefore, 24 hours of infusion was taken as the main indicator.

To intensify the process of extracting flavonoids from the leaves of Salvia officinalis, the method of sonication at the stage of soaking was used. The treatment of raw materials with ultrasound increases the release of substances from the cell by creating cavitation and turbulent flows in the mixture of the extractant and plant raw materials, as a result of which there is a rapid swelling of the plant raw material and the dissolution of the cell contents, the rate of hydration of the raw material particles increases, turbulent and vortexes appear in the boundary diffusion layer. flows, which leads to the intensification of mass transfer $[17,18]$. The processing times were 25,45 and 55 minutes. The peak yield of flavonoids from raw materials came at 45 minutes of raw material processing. The increase in the content of the test substances with ultrasonic treatment was $82 \%$ more than without ultrasonic treatment of raw materials, which allows us to conclude that the use of this method is rational to obtain the maximum extraction of flavonoids into the hood.

All the results of the selection of the optimal conditions for extraction by the maceration method are shown in Table 1.

Table 1. The results of the selection of optimal conditions for the yield of flavoids from raw materials, depending on the hydromodule, the concentration of ethyl alcohol, the time of infusion and the time of ultrasonic treatment.

\begin{tabular}{|c|c|c|}
\hline \multicolumn{2}{|c|}{ Indicator } & $\begin{array}{c}\text { Quantitative content of flavonoids, } \\
\mathrm{mg} / \mathrm{g}\end{array}$ \\
\hline \multirow{3}{*}{ Hydromodule } & $1: 10$ & 46,8 \\
\cline { 2 - 3 } & $1: 30$ & 64,6 \\
\cline { 2 - 3 } & $1: 50$ & 86,0 \\
\hline \multirow{3}{*}{ Ethyl alcohol concentration } & $40 \%$ & 80,7 \\
\cline { 2 - 3 } & $70 \%$ & 86,4 \\
\cline { 2 - 3 } & $96 \%$ & 20,6 \\
\hline \multirow{3}{*}{ Infusion time } & $18 \mathrm{~h}$. & 45,5 \\
\cline { 2 - 3 } & $24 \mathrm{~h}$. & 84,8 \\
\cline { 2 - 3 } & $72 \mathrm{~h}$. & 86,8 \\
\hline \multirow{3}{*}{ Ultrasound processing time } & $25 \mathrm{~min}$ & 123,2 \\
\cline { 2 - 3 } & $35 \mathrm{~min}$ & 151,0 \\
\cline { 2 - 3 } & $45 \mathrm{~min}$ & 182,7 \\
\cline { 2 - 3 } & $55 \mathrm{~min}$ & 176,7 \\
\hline
\end{tabular}

\section{Conclusions}

As a result of the study, a method was developed for obtaining a liquid extract of Salvia officinalis L. with the maximum yield of flavonoids in the extract, in terms of luteolin-7glycoside. A sample of raw materials with a particle size of $0.1-1 \mathrm{~mm}$ was poured with an extractant with $70 \%$ ethyl alcohol in a raw material - extractant ratio of 1:50, infused for 24 hours, the resulting extract was treated in an ultrasonic unit for 45 minutes, filtered, brought to the initial volume with $70 \%$ ethyl alcohol and analyzed by the quantitative content of flavonoids in terms of luteolin-7-glycoside by differential spectrophotometry by the reaction of complexation with aluminum chloride. The resulting technique can be used to obtain a liquid extract of sage officinalis for further production of a thick extract and use it as an 
intermediate product for introduction into dosage forms for the treatment and prevention of various inflammatory diseases.

\section{References}

1. N.N. Boyko, A.V. Bondarev, E.T. Zhilyakova, D.I. Pisarev, O.O. Novikov. Research Result. Medicine and Pharmacy. 3, 4 (2017). Russian.

2. I. Shirokova. Remedium. 4, 194 (2013). Russian.

3. U. Bhadoriya, S. Tiwari, P. Sharma, S. Bankey, M. Mourya. Asian J. of Pharm. Life Sci. 1, 1 (2011).

4. G.A.N. Melo, J.P. Fonseca, T.O. Farinha, R.J. Pinho, M.J. Damião, R. Grespan, E.L. Silva, C.A. Bersani-Amado, R.K.N. Cuman. J. of Med. Plants Res. 6, 35 (2012).

5. E. Neagu, G.P. Roman, G.L. Radu. Rev. Roum. Chim. 56, 8 (2011).

6. A. Alizadeh, M. Shaabani. Adv. Environ. Biol. 6, 1 (2012).

7. R. Khalil, Z-G. Li. Afr. J. Biotechnol. 10, 42 (2011).

8. E.I. Ryabinina, E.E. Zotova, E.N. Vetrova, N.I. Ponomareva. Analytics and Control. 15, 2 (2011). Russian.

9. E.I. Ryabinina, E.E. Zotova, N.I. Ponomareva, S.V. Ryabinin. Proceedings of VSU. 2 (2009). Russian.

10. A. Böszörményi, É. Héthelyi, Á. Farkas, G. Horváth, N. Papp, É. Lemberkovics, É. Szóke. J. Agric. Food Chem. 57, 11 (2009).

11. M.H.H. Robya, M.A. Sarhana, K.A.-H. Selima, K.I. Khalel. Industrial Crops and Products. 43 (2013).

12. A.N. Komisarenko. The method of obtaining a product with antimicrobial activity from cineole-containing vegetable raw materials (Internet). 2010. Ukrainian. URL: https://sis.ukrpatent.org/uk/search/detail/438935/

13. R.A. Orujov, R.E. Jafarova. Mediko-Sotsyal'naya Ekspretiza i Reabilitatsiya. 20, 3 (2017). Russian.

14. R.A. Orujov, R.E. Jafarova. Vestnik of VSMU. 16, 4 (2017). Russian.

15. State Pharmacopoeia 14th edition (Internet). 2018. Russian. URL: http://femb.ru/femb/pharmacopea.php

16. Zh.S. Lesovaya, D.I. Pisarev, O.O. Novikov, T.A. Romanova. Scientific bulletins of BelSU. Series: Medicine. Pharmacia. 22, 93 (2010). Russian.

17. R.R. Safin, F.V. Nazipova, A.E. Voronin, R.R. Zaitdinov. Kazan Technological University Bulletin. 18, 16 (2015). Russian.

18. E.S. Filonenko, E.S. Zibareva. Eurasian Union of Scientists. 3, 12 (2015). Russian. 